\title{
Clóvis Moura e a Sociologia da Práxis
}

Érika Mesquita

\section{Resumo}

Este trabalho vem contribuir para um (re)pensar a obra e a postura intelectual de um dos grandes pensadores brasileiros, Clóvis Moura, profícuo estudioso da história social do negro no Brasil. Analisa a conduta acadêmica deste cientista social radical e expõe, de forma incipiente, parte de sua trajetória de vida que muito contribuiu para suas acepções teóricas e práticas. Traz à tona a questão de sua tardia receptividade nos círculos acadêmicos.

Palavras-chave: Clóvis Moura, história social do negro, Brasil, negro, Sociologia da práxis.

\section{Abstract}

Clovis Moura and the sociology of praxis

This work contributes to a (re)thinking of the work and intellectual position of one of the greatest Brazilian thinkers, Clovis Moura, a very important Brazilian thinker of the Negro social history. It analyzes this radical social scientist's academic career, and it shows, as well, a part of his life story that has contributed to his theoretical and practical ideas. And it also highlights his late acceptance among the academic circles.

Keywords: Clovis Moura, Negro social history, Negro, Brazil, sociology of praxis. 
Érika Mesquita

\section{Résumé}

Clovis Moura et la Sociologie de la praxis.

Par ce travail, on veut contribuer à repenser l'oeuvre et la démarche intelectuelle de l'un des grands chercheurs brésiliens, Clovis Moura, dont les études sur l'histoire sociale du Noir au Brésil sont fructueuses. On y analyse la démarche académique de ce spécialiste radical des sciences sociales et l'on présente de forme succinte une partie de la trajectoire de sa vie qui l'a beaucoup aidéà mettre en place ses acceptions théoriques et pratiques. On souligne également le fait que les milieux académiques ne l'ont reconnu que tardivement.

Mots-clés : Clovis Moura, histoire sociale du Noir, Noir, Brésil, Sociologie de la praxis. 
$\mathrm{Q}$ uando começamos a pensar sobre Clóvis Moura, deparamos com muitas indagaçôes. As mais freqüentes, de meus colegas alunos de pós-graduação, eram "quem foi Clóvis Moura", e "no que ele contribuiu para pensar o Brasil?" Ao mesmo tempo, havia pronunciamentos eufóricos, principalmente de professores, tais como: "que bom que alguém se lembrou dele". Bem, diante deste quadro - esquecido ou preterido -, começamos a refletir sobre suas proposições. Este artigo é fruto de nossa dissertação de Mestrado em Sociologia sobre a obra deste autor, e não tem a pretensão de ser exaustivo ou de dar uma resposta conclusiva a respeito do intelectual Clóvis Moura. Nossa proposição é dar o pontapé inicial para muitos outros estudos sobre sua obra. Buscaremos trazer algumas possíveis hipóteses de análise da trajetória intelectual - pode-se dizer radical $-{ }^{1}$ deste autor, acima de tudo ético.

Como pretendemos resumir sua compreensão de Brasil, e estamos analisando algumas de suas interpretações com o intuito de revelar suas proposições, sua história de vida ganha relevo. Este recorte de estudo traz à tona partes, consideradas por nós, importantes de sua biografia.

Clóvis Steiger de Assis Moura nasceu no outono de 1925, em Amarante, Piauí, membro de uma família de classe média-baixa (na linguagem cabocla seria o equivalente a remediado, isto é, nem pobre, nem rico). Filho de mãe branca e pai negro tem, entre seus antepassados, um barão do império prussiano, seu bisavô Ferdinando vön Steiger; pelo lado paterno, a escrava Carlota, sua avó, diga-se em tempo, escrava de seu avô, mais um dos muitos senhores de engenho do Nordeste açucareiro. Clóvis, ainda criança, muda-se com a família para Natal (RN), onde residiu de 1935 a 1941. Inicia seus estudos num colégio de padres maristas, o Colégio Santo Antônio. Ainda muito jovem funda, à revelia dos irmãos maristas, o Grêmio Cívico-Literário "12 de Outubro", onde eram realizadas reuniões semanais para discussão de literatura e política. Segundo Moura, o grêmio cresceu e prosperou, chegando a possuir quarenta membros, participantes ativos, "cada um com seu 
patrono à maneira da Academia Brasileira de Letras". ${ }^{2}$ Comenta, ainda, que "o Grêmio contou com sócios honoráveis, como Luís da Câmara Cascudo, Elói de Souza, dentre outros autores regionais de renome". Possuiu também um jornal literário de nome $O P o-$ tiguar, sob sua direção, no qual publicou o primeiro de muitos artigos sobre o Brasil, este versando sobre a Inconfidência Mineira.

Quando Clóvis Moura e seu irmão se mudaram para Salvador, em 1942, finda-se o Grêmio, muito conhecido pelos debates e publicações literárias. Na Bahia, Clóvis não chega a graduar-se em Humanidades naquele ano, ${ }^{3}$ e ingressa na carreira jornalística por meio do jornal O Momento, diário do Partido Comunista Brasileiro - PCB. É quando há o contato com o PCB, que se constitui na oportunidade para que ele se aprofundasse nas teorias marxista e pecebista da III e IV Internacionais. Já em 1945 torna-se militante e em 1947 elege-se deputado estadual pelo Partido, mas tem sua candidatura cassada pelo Tribunal Eleitoral devido a uma manobra política proveniente dos partidos de ocasião, em torno de um comício no qual estava em Juazeiro, no dia $1^{\circ}$ de maio. Sabemos que houve, em 1947, mais um dos cancelamentos do registro do Partido Comunista, partido pelo qual se elegera.

Por conta desse acontecimento político, Moura transfere-se para São Paulo em 1949, e começa a atuar na Frente Cultural do $\mathrm{PCB}$, organismo que reunia Caio Prado Júnior, Villanova Artigas, Artur Neves, dentre outros intelectuais. Além de militar no Partido Comunista, Moura profissionalmente atua como jornalista, trabalhando para Samuel Wainer e, posteriormente, para Assis Chateaubriand, nos Diários Associados. Concomitante a sua atividade profissional, pesquisava sobre a rebeldia negra, a luta de classes no período colonial, tendo como foco o importante e ativo papel do negro na formação da nação, não só do ponto de vista culturalista, que começava a ser abordado no momento, mas - e principalmente - social, desdobrando-se para os planos político e econômico. Em 1959 publica seu primeiro e marcante livro, Rebelióes da senzala.

Foi com esse pioneiro livro, revisionista da escravidão, bem como da história social do negro, que Clóvis Moura se inseriu no cenário intelectual brasileiro, sendo que as luzes da ribalta nacional tardiamente voltaram seu foco para ele. A questão que se coloca é: por que o autor foi preterido da discussão acadêmica, principalmente logo após sua "inserção" como mais um pensador da escravidão e da história do negro no país? Talvez a resposta a este questionamento esteja na própria leitura feita pelo autor da história so- 
cial brasileira. Com grande acuidade e criticidade, verificou que para a construção desta sociedade cobra-se um alto custo dos setores subalternos, em especial dos negros; esta leitura era incômoda para as classes dominantes.

O fato é que seu primeiro livro, Rebelioes da senzala foi, eufemisticamente, pouco acolhido pelos intelectuais brasileiros, pertencentes ou não ao Partido Comunista, que resistiram à sua tese. Talvez por suas acepçôes estarem em desajuste com o stalinismo ${ }^{4}$ pregado pelo PCB, sua ligação com o Partido nunca foi de aceitação das teorias divulgadas pela Internacional Comunista, daí sua aproximação das análises de Brasil feitas por Caio Prado. ${ }^{5}$ Assim como este autor, suas análises também utilizam o marxismo, mas apenas como instrumento para diagnosticar as realidades contraditórias das diversas fases históricas do país, levando em consideração, principalmente, a questão racial. E, por conta de sua posição, digamos radical, dentro do "Partidão", desde logo, por causa de suas interpretações consideradas aberrações por seus companheiros de partido, Moura começa a ser isolado ou "desqualificado" dentro da verdadeira e profícua bandeira de luta do PCB - a luta de classes que, à época, para os partidários do comunismo, nada tinha a ver com questão racial. Segundo Moura, os PCs brasileiros, bem como os latino-americanos, tinham [e de certo modo ainda têm] dificuldades em entender a questão "raça"/classe que envolve a problemática do afrodescendente brasileiro, bem como do afrodescendente latino-americano (Moura, 1994).

\section{$\mathrm{O}$ intelectual radical e a Academia}

Sobre a questão "intelectuais e os partidos de esquerda", Marco Aurélio Garcia coloca uma distinção entre o "intelectual de partido" e o intelectual "simpatizante". Para Garcia, o "intelectual de partido" é aquele que segue à risca a disciplina imposta pelos ditames internacionalizantes vindos do Partido Comunista russo; já o "simpatizante" não tende ao mesmo rigor. Ainda em sua análise, entende também que a separação entre "intelectual de partido" e "simpatizante" pode ser arbitrária, pois amiúde os dois conceitos se fundem e se confundem. Garcia apresenta exemplos da forma "simpatizante" de intelectual de esquerda:

Pablo Neruda, por exemplo, morreu militante e dirigente do PC chileno, e Jorge Amado chegou a ser deputado do Partido Comunista Brasileiro, mas seus perfis se ajustam mais aos de "simpatizantes" do que pro- 
priamente aos de "intelectuais de partido". No caso de Amado, a crise do movimento comunista dos anos 50 , que provocaria tamanhos desgastes em suas fileiras e entre os "simpatizantes", acabou por afastá-lo do PCB. [...] Caio Prado Júnior, que também foi deputado do PCB, a despeito de ter produzido uma das mais significativas obras sobre a realidade econômica, social e política do Brasil, sempre foi um marginal no interior do $\mathrm{PCB}$, na medida em que sua produção historiográfica contraditava fundamentalmente o modelo de interpretação vigente no PC sobre o caráter da sociedade brasileira”. (Garcia, citado em Soares, 1985:98)

O interessante é percebermos que o "intelectual de partido" possui, na acepção de Garcia, um sentido muito estrito, referindo-se sempre a um intelectual acadêmico, desconsiderando o intelectual "radical". Utilizando a intelecção de Garcia para analisar o intelectual Clóvis Moura, seguramente este se enquadraria na ala dos intelectuais "simpatizantes", que tal como Pablo Neruda, Jorge Amado e Caio Prado, não seguia disciplinadamente os ditames do Partido Comunista. Com isso podemos igualmente explicar a marginalização de Moura no interior do Partido. Garcia expóe que os intelectuais que pretenderam assumir seu pensar individual acabaram por sofrer de uma marginalidade que o "espírito de partido" carrega.

As relações intelectuais/partido aparecem também subsumidas nas fórmulas "o partido como intelectual coletivo", com o que se pretende sublinhar o caráter "social" da elaboração teórica e minimizar as intervençōes individuais. Sem subestimar a importância desta proposta metodológica, é importante assinalar que ela tem ocultado, na maioria dos casos, um processo monocórdico de reflexão, onde as dissonâncias teóricas são estigmatizadas como verdadeiras heresias ou, simplesmente, confinadas a posições onde não têm repercussão. Trata-se da aplicação dos princípios do "centralismo democrático" à atividade intelectual. (ibidem:99)

Esbarramos também em outra questão, a do intelectual inserido na universidade e daquele autônomo. Mas, além da condição de estar ou não no meio acadêmico, essa situação carrega consigo a ilação de uma ideologia particular, que no caso de Moura é a de não estar à venda (quer dizer, a serviço do capital), de poder ter uma desvinculada e mais ampla liberdade de expressão, sem se preocupar em agradar esse e desagradar aquele, portanto, de possuir integridade, no significado mais amplo desta palavra. Logo, de postar-se na contramão do capitalismo e de suas estruturas, no caso a academia. A postura do autor era a de buscar conhecer a realidade e a partir dela produzir conhecimento por meio dos ques- 
tionamentos feitos, sem se preocupar com carreira acadêmica, política ou militância.

Inserimos a militância nessa nossa abordagem pois Moura, assim que amadureceu, podemos dizer, intelectualmente, como ele mesmo nos revela, conseguiu verificar a incongruência entre livre pensador e militante, ou seja, o verdadeiro intelectual em sua concepção e para evitar possíveis bifurcações de seu pensamento e conduta, não deve militar em nenhum partido. Esse patamar de interpretação só pode ser alcançado pela vivência e pela militância. Ele entende que é possível ser crítico e ser de "esquerda" sem pertencer a um determinado partido, e ele prefere assim. Desde a década de 80 se desvinculou da militância, passando a contribuir intelectualmente para uma ou outra causa e proposta, mas sem levantar nenhuma bandeira partidária, a não ser aquela dos excluídos do sistema, principalmente negros e não-brancos. Mas não podemos esquecer de observar que esta postura é individual de Clóvis Moura, e que outros intelectuais conseguiram militar e continuar sendo pensadores críticos, como Caio Prado Júnior e Florestan Fernandes.

A questão aqui não é desmerecer os verdadeiros intelectuais acadêmicos, mas sim sublevar a modéstia e a coragem que possuiu nosso autor, que pregava e vivia o que realmente deveria ser a figura do intelectual, em nosso entendimento, o de exercer diariamente o papel da rebeldia, sendo um criador e procriador do desassossego e da dúvida, tomando partido do progresso das minorias, que no seu caso, são os negros na sua luta contra o racismo, logo, contra a desigualdade e o capitalismo. $\mathrm{O}$ autor não se preocupou em fazer carreira acadêmica, mas sim em contribuir com uma interpretação, no mínimo, autêntica da realidade brasileira, e acima de tudo em bases dinâmico-rebeldes, isto é, com uma postura crítica e uma proposta radical de mudança da sociedade. Portanto, podemos aplicar o conceito de "intelectual ${ }^{6}$ revolucionário" a Clóvis Moura, com todo o peso e o significado que este conceito possui e agrega. Konder, analisando o papel do intelectual, escreve: "O artista, o escritor, o intelectual não devem 'servir aos donos da vida'. [...] Devem, no entanto, preservar sua autonomia individual" (Konder, 1991:48). Ainda utilizando as acepções de Konder, podemos adotá-las para averiguar a contribuição de Clóvis Moura e seus estudos para o revisionismo da história do negro no país:

A concepção da história como um processo no qual a dilaceração da comunidade humana, a divisão social do trabalho, a competição em torno 
da propriedade privada, a exploração e a opressão impedem os seres humanos de aproveitarem a crescente dominação das forças naturais para se tornarem mais livres é uma concepção que cobra daquele que a adota uma reflexão mais crítica a respeito dos caminhos que os homens têm percorrido e uma disposição mais resoluta no sentido de superar o peso morto do passado e forjar uma história nova, diferente, melhor. (ibidem:131)

Daí podermos pensar no grande incômodo que, para muitos, caracterizou as proposiçôes mourianas. Neste ínterim, ressaltamos o pano de fundo histórico da cultura brasileira na qual se inclui a fase de sua obra mais representativa.

A década de 1960 foi marcada, a princípio, por uma tentativa de reorganização mais democrática e justa da sociedade por parte de um setor social que, como sabemos, não obteve sucesso, devido ao contragolpe de parte das elites, concretizado na tomada do poder pelos militares e sua conseguinte ditadura, com isto evitando o fim de alguns privilégios e a modificação da estrutura social vigente.

Para esta análise, buscamos em Carlos Guilherme Mota (2000) a periodização que para nós mais cabe aos estudos mourianos, que se inserem na "Era de ampliação e revisão reformista" que Mota data entre 1957 e 1964 . Esse momento caracteriza-se pelo revisionismo nos estudos sociais, principalmente em leituras histórico-sociológicas, e um dos temas desta grande releitura foi a revisão da história do negro. Fora um momento fecundo nas Ciências Sociais no país, pois a escola de Florestan Fernandes dá os primeiros, de muitos frutos. Também não podemos deixar de mencionar, para o fértil momento, a contribuição profícua da política desenvolvimentista que atingiu também a vida cultural e universitária do país. ${ }^{7}$ De acordo com a análise de Mota, esse período é um momento em que os estudos históricos se unem aos estudos sociológicos e políticos. Observa:

A temática central dessas produções [da produção intelectual dessa fase] está ligada ao estudo das mudanças sociais e políticas no Brasil, em perspectiva histórica. Muitos autores foram diretamente ao cerne do processo histórico, procurando estudar a fisionomia própria (ou não) dos modos de produção no Brasil, e suas manifestações nas diversas instâncias da realidade, não descuidando totalmente da inserção do Brasil na economia mundial. A perspectiva geral era antiimperialista, mas o estudo cuidadoso da temática da dependência ainda não se impusera. (Mota, 2000: 41)

É nesta fase que também ocorre a institucionalização dos quadros intelectuais. Ainda utilizando suas análises, concordamos 
que: "A tradição radical [de intelectuais] - que se opõe à tradição afortunada - não se constitui em setor dominante, mas em fração diminuta da intelectualidade" (ibidem:51) Então, mesmo em momentos de transição, a locomoção dos intelectuais, ou seja, do mundo da cultura, é lenta com relação à maior velocidade da esfera da produção; logo, os momentos de crise não foram suficientes para acelerar uma transformação maior na esfera dos intelectuais vinculados ao sistema. O que ocorreu foi que os intelectuais tradicionais tornaram-se "intelectuais orgânicos" de uma determinada classe social, neste caso, muitos da classe dominante.

$O$ poder da academia também se verifica nas citações; foi o que notamos em muitas obras de inúmeros intelectuais brasileiros que não citam Clóvis Moura, principalmente nas décadas revisionistas de 70 e 80 . Podemos cogitar que talvez não tinham realmente o conhecimento de sua análise, mas não podemos descartar a possibilidade de não citá-lo porque este autor não fazia parte do seleto grupo dos intelectuais vinculados à academia. Interpretamos essa preterição como sendo uma questão de poder, ou seja, Moura era um intelectual autônomo, isto é, sem poder, então, citava-se um autor ou não como forma de fazer política. Muitos, digamos, pseudo-intelectuais por pura demagogia citavam as obras de autores vinculados a determinados grupos e a instituições de pesquisa, por suposto, recheados de poder, com outra intenção desta de contribuir para a compreensão das esferas da vida, das estruturas e relações sociais da sociedade, e sem a pretensão de contribuir de alguma forma para buscar a modificação e transformação da realidade em prol da construção da verdadeira democracia, e da nação.

Estamos pisando em terreno minado, pois caímos na velha discussão da parcialidade ou imparcialidade das Ciências Sociais, e conseqüentemente do intelectual, o que não é nossa pretensão fazer, mas aproveitamos para lançar mão da acepção de Michael Löwy, com que concordamos:

Entretanto, contrariamente ao que permite deduzir Mannheim, que tende a absolutizar esta autonomia, não há intelligentsia verdadeiramente "neutra" e acima das classes. A flutuação dos intelectuais, como aquela dos balóes de ar quente na noite de São João, é um estado provisório: eles terminam, geralmente, cedendo à lei da gravidade, sendo atraídos por uma das grandes classes sociais de luta (burguesia, proletariado, às vezes campesinato). (Löwy, 1979:2)

No caso de Moura, o seu balão caiu na classe proletária e excluída, que é a da maioria dos negros brasileiros. Deparamos aqui 
com o seguinte questionamento: por que essa exclusão? E é em cima dessa desigualdade entre negros e brancos gritante no Brasil, que o autor parte para teorizar o preconceito racial, e o grande e importante outrora papel dos negros na transformação da estrutura brasileira pretérita, bem como de seu caráter relevante para que haja as vindouras e futuras transformações.

Moura incorre no viés hegeliano de marxismo, conjetura o passado permeável à razão, e assim apropria-se do fato histórico consubstanciado para entender o processo de construção nacional. Sendo assim, a nação apresenta-se como uma etapa necessária na ultrapassagem das relaçôes capitalistas de produção. Logo, nosso autor explica a realidade social brasileira a partir de bases materiais e de relações de classe, bem aos modos marxianos, mas deixando bem claro que apenas utiliza o marxismo como ferramenta para pensar o Brasil, e não o seu contrário, o de encaixar o país num modelo engessado de marxismo. Daí sua proximidade com as análises de Caio Prado Júnior.

Ele questiona a sociologia acadêmica em sua obra $A$ sociologia posta em questão, escrita em 1971, publicada no Brasil em 1978. É interessante analisarmos suas colocações nesse trabalho para podermos entender sua postura intelectual. Moura divide as Ciências Sociais, enfocando, principalmente, a Sociologia em duas categorias: a acadêmica e a dinâmico/radical da práxis. A sociologia acadêmica é aquela estreitamente vinculada às classes dominantes e divulgadora de sua ideologia. No seu entender, é aquela que apresenta soluções parciais para diversos tipos de conflitos, procurando bloquear soluçóes mais radicais. Ainda em sua generalização sobre a sociologia acadêmica, deslinda que esta não contempla a dinâmica da sociedade e não contém a crítica radical ao sistema capitalista, e expõe o por que da sociologia acadêmica não poder conter a radicalidade:

[...] a sociologia acadêmica pode, no máximo, em determinados momentos, ser uma ideologia crítica de alguns segmentos, das classes dominantes, porém nunca uma ciência que esteja em consonância com o ritmo do dinamismo emergente da sociedade. É sempre um elemento estruturalmente limitado porque não acompanha as contradições que se manifestam em conseqüência do próprio desenvolvimento do seu objeto de estudo. Em outras palavras: a sociologia acadêmica, em determinados momentos, pode, quando muito, refletir apenas uma consciência crítica, reformista, mas nunca uma consciência revolucionária. (Moura, 1978:11-12) 
$\mathrm{O}$ autor compreende a sociologia acadêmica engessada pela estrutura estruturante, por assim dizer, do sistema capitalista, e desde logo, sem a radicalidade, dinamicidade e plasticidade que a sociologia dinâmico/radical ou sociologia da práxis revolucionária, entendida pelo autor como sendo a verdadeira sociologia, possui. E, justamente, fica a cargo dessa sociologia dinâmico/radical uma proposta real de mudança social, bem como de uma nova estruturação das Ciências Sociais. Escreve:

A sociologia acadêmica reflete, interpreta e justifica, assim, na sua estrutura conceptual e na sua aplicação prática, a inércia social e o conservadorismo político nas suas diversas conotações. Desta forma há necessidade, nesta constelação de teorias que configura a decomposição do pensamento social e das ciências sociais acadêmicas, de uma reformulação radical dessas categorias. [...] Na sociedade capitalista - especialmente na sua etapa atual - qualquer tipo de reformismo é, portanto, uma forma refinada de impedir a revolução social. Daí o gradualismo da Sociologia acadêmica funcionar como força de retrocesso ou estagnação social. Sua vinculação com a ordem estabelecida impede-a de colocar-se ao lado daquelas forças, grupos ou instituições que são a expressão da necessidade de projeção de uma nova sociedade. Nasce, então, toda uma sistemática justificatória do que existe e condenatória do vir a ser que passa a ser considerada utopia ou pensamento quiliástico. (ibidem:116-117)

Por essas análises sobre as Ciências Sociais institucionalizadas ou acadêmicas, tecidas por nosso autor, podemos compreender a posição tomada por ele, que dentro do que entende por ser intelectual, fez jus ao seu papel ou missão de intelectual, pois, não só trabalhou teoricamente, mas principalmente pôs em prática suas intelecções. Para Moura, a intrínseca ligação entre a academia e a classe dominante da sociedade capitalista pode ser facilmente detectada pelos fomentos destinados a tal ou qual projeto feitos por agências mantenedoras estatais ou privadas que, por suposto, seguem a cartilha racionalista e teoricista da ideologia capitalista. Colocando a academia numa posição de instituição tática subordinada e, portanto, auxiliar da manutenção da estrutura em vigor, aponta que:

[A sociologia acadêmica é] uma técnica refinada que racionaliza as suas contradiçôes. Os institutos de pesquisas, as fundações de auxílio, todo o conjunto de instituições que beneficiam esse tipo de atividade através de compensadores financeiros, corrói a visão dinâmico/radical do cientista social, deixando-o ideologicamente desarmado para entender a irracionalidade global do sistema, pois, através de um condicionamento habilmente preparado, vai sendo alienado pelo próprio reflexo das idéias dominantes e passa a aceitar como ciência - embora isto não se manifeste 
num plano consciente - apenas aquelas técnicas altamente refinadas que são elaboradas nos círculos universitários. (ibidem:12)

Neste pequeno trecho, parece-nos que ele mesmo se questionou sobre a sua "exclusão" do debate intelectual no meio acadêmico, talvez por apresentar uma posição ímpar da praticada nesse meio. Nessa análise, nos dá a impressão que o intelectual, para ser reconhecido por seus pares, deve ser moldado de uma mesma forma, com um mesmo molde, ou seja, dentro de determinados padrões. Caso essa modelagem ou padrão não seja seguido à risca, como numa linha de montagem, o produto em deformidade é descartado e ou inutilizado. Cabe aí o seguinte questionamento: podemos entender que, sendo assim, só é reconhecido como intelectual aquele que aceita a institucionalização das Ciências Sociais, fazendo parte dela em algum momento? O capitalismo corrói todas as esferas da vida, infectando também a esfera intelectual e, portanto, apresenta-se bastante difícil digressionar-se de sua abrangência e, neste viés, observa Giannotti que a esfera intelectual está atrelada à lógica capitalista:

O autor escreve um valor-de-uso, cujo direito de reprodução cede ao editor; este o reproduz em milhares de exemplares com o fito preciso de auferir lucros, uma parte dos quais cede ao escritor. Sob esse aspecto, cientista e autor surgem como uma espécie de latifundiário ou de usurário transferindo ao capitalista industrial o direito de explorar um monopólio. (Giannotti, 1977:24-25)

Entendemos que, devido a sua postura radical contra o capitalismo, Moura adotou a posição de intelectual radical, ou seja, minimamente ligado ao sistema. Devemos ressaltar que Clóvis Moura, como tantos outros intelectuais, teve problemas quanto ao recebimento de direitos autorais. Numa destas pelejas com editoras, doou mais de duzentos exemplares, não vendidos pela editora e que iriam ser incinerados, para o MST - Movimento dos Sem-Terra.

Ainda analisando o intelectual Clóvis Moura, colocamos em questão o assim denominado por Bourdieu "campo intelectual". Entendemos que o campo intelectual do qual fala Bourdieu é o que conhecemos como campo intelectual-acadêmico, e não campo intelectual como um todo. Bourdieu expõe em seu conceito de campo intelectual, que este se caracteriza

em interesses específicos, não somente em Paris, mas também em Moscou, cargos acadêmicos ou contratos editoriais, resenhas ou cargos universitários, e também sinais de reconhecimento e gratificações freqüen- 
temente imperceptíveis para quem não pertence ao universo em questão, mas através das quais ocorrem todos os tipos de pressóes e censuras sutis. (Bourdieu, 1983:56)

Podemos entender, de acordo com a compreensão de Bourdieu de campo intelectual, que seu conceito é amalgamado e generalizado, não cabendo nele a ala dos intelectuais radicais, desvinculados de instituições de ensino e pouco seduzidos pela fama ou reconhecimento de sua genialidade intelectual. Podemos concordar com o conceito de campo intelectual somente em dois aspectos: quando Bourdieu ressalta as percepções dadas aos indivíduos que estão inseridos neste campo, que mesmo os intelectuais radicais sabem entender e decodificar os códigos daí provenientes, e pela questão dos jogos de poder e sua vinculação com o campo político. Devemos, então, levar em conta essas particularidades no que diz respeito ao campo intelectual como um todo, mas sempre considerando as diferenças entre intelectuais acadêmicos e radicais, que, por suposto, comungam de distintos interesses, quer em Paris, Moscou ou em outra parte do mundo.

Clóvis Moura está claramente preocupado com a transformação social, e com isso norteia sua postura intelectual entendendo que o pensador independente possui maiores e mais concretas possibilidades de fomentar a mudança da sociedade, pois não está preso a nenhum tentáculo do sistema. Em sua ilação, expõe que "o sociólogo profissional usa de um conjunto de técnicas para servir à estrutura; não é um cientista independente que procura uma práxis para transformá-la" (Moura, 1978:28). Moura não se aliava ao Estado 9 (entendido por ele como expressão das elites); muito pelo contrário, questionava-o diletantemente, juntamente com suas instituições, que, para ele, se mostravam coniventes com o atual sistema. Ele guiou-se por uma ação vinculada a uma proposta extremamente radical de mudança, atitude esta que foi entendida por muitos como sendo anticientífica. Analisamos a marginalidade, principalmente de suas primeiras obras dentro da academia durante algum tempo, ${ }^{10}$ e, por este viés, sua postura.

Diante da então sociologia acadêmica, Moura chega ao prognóstico nefasto da crescente fragmentação do conhecimento. Nesta está intrínseco um grande problema, a falta de perspicácia investigativa dos cientistas, que resulta numa estreiteza ideológica intelectual, lógica esta imanentemente fomentada pelo capitalismo. Escreve: 
O refinamento metodológico, a necessidade de corpos de especialistas em aspectos menos relevantes, cada vez mais requintados e bem remunerados, no entanto, conduz à apatia ideológica e à miopia teórica. [...] Apesar [dos intelectuais] trabalharem em equipe são cada vez mais introvertidos, virados para dentro de si mesmos, vendo em cada colega mais um concorrente na carreira universitária do que um colaborador científico. (ibidem:27)

Quanto à questão da profissionalização do intelectual, o autor observa que, de uma certa forma, o assalariamento do intelectual contribuiu para que ele, juntamente com outros trabalhadores, pudessem, juntos, questionar a estrutura social vigente, na busca pela real democracia e por uma renovação social. Mas, ele depara com o fato de que a ordem dos intelectuais não é coesa, e muitos sucumbiram às benesses do capital e abandonaram o barco da mudança social, chegando a desqualificá-la por completo. Em sua análise, para realmente termos verdadeiros intelectuais é preciso buscar a concretização de uma sociedade mais justa, nos quais estes possam realmente desempenhar seu papel, que muitos se olvidaram (Moura, 1978).

Walnice Galvão, em sua acepção incisiva sobre o intelectual acadêmico brasileiro, expõe:

[...] que, com maior ou menor boa vontade, voluntariamente ou a contragosto e mesmo com raríssimas exceções honrosas, os intelectuais brasileiros aderem à ideologia da classe dominante e procuram não enfrentar o Estado, do qual depende diretamente sua subsistência. (Galvão, citada em Coutinho, 2000:53)

É, no mínimo, interessante uma das ilações a que chega Pécaut (1990) sobre o "mundo" dos intelectuais, que estes "formam um mundo heteróclito", ou seja, um mundo extravagante. Não concordamos com essa acepção de Pécaut, pois entendemos que o "campo intelectual" é, assim como outros campos específicos, pululado de linguagens e códigos só reconhecidos e decifráveis pelos seus componentes, mas esta característica não permite dizermos que o mundo dos intelectuais é um mundo singular; pelo contrário, é o mesmo mundo, os intelectuais são cidadãos como os outros cidadãos, mas com uma significante particularidade, a possibilidade de questionar o que está dado, o que está no lugar. O legítimo intelectual tem a função de colocar as "idéias fora do lugar", tirá-las da "ordem”, e não só as idéias, mas essencialmente as atitudes, a começar pela sua, no fomento de um movimento verdadeiramente democrático que transforme a sociedade. 
Clóvis Moura seguiu à risca a premissa de que o intelectual deve ser solidário às minorias, aos subjugados, aos oprimidos, aos discriminados, quando em seu trabalho intelectual buscou enaltecer a importante participação do negro na constituição da sociedade brasileira, este discriminado, preterido etc., e sua luta ofuscada, principalmente no que tange à incansável batalha para pôr fim à escravidão. Colocou-se também como um dos porta-vozes dos negros em sua luta de séculos por uma verdadeira cidadania social e política, quando questiona o modelo atual de globalização, o capitalismo dependente brasileiro, o conceito de "democracia social" 11 e a historiografia "oficial" que ofuscou e esvaziou a importante participação negra na construção do Brasil.

\section{Compreensão e reconhecimento tardio de um grande intérprete do Brasil}

Percebemos que é a partir da década de 80 que a obra de Moura passa a ser mais consultada e compreendida. Talvez a resposta a este congelamento e descongelamento de sua obra se dê pelo próprio processo social, que fez com que muitas idéias fossem postas à prova, e também à evolução das Ciências Sociais como um todo, principalmente as pesquisas, que trouxe à tona um outro lado da história social brasileira, fazendo com que as pioneiras acepções mourianas não fossem vistas mais como um simples trabalho romântico e diletante, ou de qualidade científica duvidosa.

Schwartz, em fins da década de 1980, exalta que os trabalhos sociológico-historiográficos mais interpretativos da rebelião negra $^{12}$ foram os de Clóvis Moura, dentre aqueles feitos pelos revisionistas da história do negro no Brasil. Escreve Schwartz:

O interesse pela resistência escrava aumentou muito nas duas últimas décadas [70 e 80]. Isso aconteceu, em parte devido à conscientização cada vez maior da desigualdade racial no Brasil, a uma pesquisa autocrítica de exemplo e tradição historiográficos feita pelos intelectuais revisionistas e afro-brasileiros e a um clima histórico geral no qual cresce o interesse pelos atos dos escravos. [...] Mais interpretativos são os trabalhos de Clóvis Moura, que se concentram nas comunidades de escravos fugitivos (quilombos) e nas rebeliōes. (Schwartz, 2001:39-40)

Para Lilia Moritz Schwarcz, a interpretação de Clóvis Moura é a primeira de uma série de outras que surgiriam posteriormente, principalmente das décadas de 60 e 70, provenientes da chamada "Escola Paulista", com os trabalhos de Roger Bastide e Florestan 
Fernandes. Reconhecendo o pioneirismo de Moura, Lilia Schwarcz deslinda que:

[...] alguns procuravam mostrar os sofrimentos por que passava o negro cativo, bem como sua revolta com relação à própria condição. Clóvis Moura faz a primeira tentativa no sentido de entender os movimentos de rebeliāo negra. (Schwarcz, 1987:20)

Também para Carlos Magno Guimarães, a análise mouriana foi a pioneira nos estudos valorativos da rebeldia negra, contribuindo, por sua vez, para a liquidação da escravidão e, desde logo, para que houvesse a transição do trabalho compulsório para trabalho livre e assalariado. Relata Carlos Magno Guimarães:

Clóvis Moura, dentro desta corrente, merece destaque por ter sido quem, pela primeira vez, afirmou a importância do estudo das várias formas de rebeldia escrava para se entender a dinâmica da sociedade escravista. É dentro desta perspectiva que vê o escravo rebelde enquanto elemento de desgaste do escravismo, contribuindo para a transição para o trabalho livre”.(Guimarães, 1988:20)

Daí a importância da acepção de Clóvis Moura, pioneira em ressaltar a história e a contribuição dos negros à nação brasileira de uma forma revisionista da sua ação como ator social ativo, elencando suas revoltas e participações em inúmeros levantes. A maior força dos seus estudos está em identificar a grande atuação do negro, esboçando resoluçóes, mas, detidamente se atém a sublinhar o papel do negro como ator social no processo de transformação da sociedade escravista, bem como na capitalista. $\mathrm{O}$ autor buscou conhecer a sociedade brasileira com o intuito de seriamente tentar desvendar os liames obscuros de sua formação, com relação ao negro. Dedicou-se a diagnosticar imperfeições pelas diversas veredas interpretativas oficiais, indicando-as e, concomitantemente, pesquisando rigorosamente vias alternativas que, melhor categorizadas, pudessem verter-se em caminhos seguros na interpretação da história do negro no país. Nas palavras de Antônio Cândido:

A grandeza de uma literatura, ou de uma obra, depende da sua relativa intemporalidade e universalidade, e estas dependem por sua vez da função total que é capaz de exercer, desligando-se dos fatores que a prendem a um momento determinado e a um determinado lugar. (Candido, 2000:41)

O intelectual Clóvis Moura é, com certeza, um intérprete relevante da história brasileira, e sua obra uma profícua contribuição para se pensar o Brasil. Atualmente podemos dizer que sua contri- 
buição para se pensar sociologicamente a história da formação do país, tendo como premissa a história crítica e revisitada do negro, conseguiu atingir o zênite das respeitáveis interpretações do Brasil, ou seja, o de gerar desdobramentos por meio de seguidores e mesmo críticos.

Atualmente, muitos sociólogos e historiadores compreendem a grandeza de suas proposições, quer em concordância ou tecendo críticas, e dando forma a outras interpretações com base na sua. Muitos movimentos negros tomam suas premissas como fundamentação teórica para nortear suas ações nas diversas lutas sociais que travam. Contudo, poder balizar movimentos negros em prol de uma verdadeira democracia e, mesmo tardiamente, serem valorizadas suas intelecçôes no meio acadêmico, significa o reconhecimento deste singular intelectual como mais uma das importantes figuras da inteligência brasileira.

A obra de Clóvis Moura é atuante em alguns dos muitos movimentos negros, principalmente na UNEGRO - União de Negros pela Igualdade. Ressaltamos que a UNEGRO busca exclusivamente nas obras de Clóvis Moura sua fundamentação teórica, no entender de que a sociedade e o Estado brasileiros têm no racismo um de seus pilares de edificação e formação. Diante deste quadro nefasto, Moura propõe uma "mudança radical" do sistema econômico e da estrutura social. Dennis de Oliveira, membro da Coordenação Estadual, da Executiva Nacional e um de seus fundadores, comenta:

Clóvis Moura fez uma análise que a gente acha interessante do racismo brasileiro [...]. Essa idéia que o Estado brasileiro foi formado com base racista. [...]. É também uma homenagem ao Clóvis Moura [...]. A questão racial para Clóvis Moura não é mais um estudo. É o estudo dele. E a gente acha uma injustiça da academia com ele. Eu acho que ele deu grandes contribuiçóes, porque ele sistematizou, ele se debruçou sobre o tema. Outros também se debruçaram, mas tem outros temas também, não foi o tema central. (Depoimento citado em Calderano, 2002:100)

Segundo a leitura de nosso autor sobre as revoltas negras, principalmente no período colonial, o negro apresentou sua potencialidade na modificação do Estado brasileiro e criação de uma verdadeira nação. E, talvez seja a grande utopia do nosso autor a transformação radical do Brasil, encabeçada por aqueles que são duplamente oprimidos, os negros. Essa abordagem de Moura serve como inspiração e argumento para a UNEGRO nos debates so- 
bre a questão racial e, desde logo, social no país. Nas palavras de Dennis de Oliveira:

Você não vai superar o racismo se for mantido esse Estado brasileiro essa é uma discussão nossa. Essa foi a grande inovação que a UNEGRO colocou. Lógico, você vai lutar por políticas públicas de combate ao racismo, ação afirmativa... nós estamos nessa luta, sem dúvida. Agora, nós temos a convicção que sem mudar esse Estado brasileiro, essa estrutura básica, o racismo não acaba. Pode melhorar, mas não acabar com o racismo. (ibidem:108)

Moura, deslindando a problemática racial, questiona também, em sua análise, a dependência econômica do país e suas conseqüências nefastas para a ocorrência da democracia em todos os sentidos. A questão é que nosso autor dá crédito à revolução proletária com o intuito de modificar o modelo atual capitalista, que traz consigo a desigualdade social e, desde logo, dando ênfase às diferenças de cor da pele, mas não de uma forma romântica, e sim madura e científica, embasado nos estudos que fez do pretérito e da atual realidade. Ele crê que a Revolução acontecerá, mas não será para agora, e que virá como resultado de um processo lento de deterioração da sociedade que vem se apresentando, e de uma conscientização proveniente da periferia do capital. E, essa revolução, no seu entender, será comandada pela classe que é majoritariamente pobre e duplamente oprimida quer social e etnicamente, que são os negros (Moura, 1994).

Como podemos perceber, felizmente as análises feitas por Clóvis Moura, mesmo não canônicas, e repletas de dissonâncias com o pensamento historiográfico e sociológico "oficial" desde a época de sua aparição, vem paulatinamente galgando preciosos degraus no score das mais autênticas e fecundas interpretações do Brasil. Sua postura crítica e radical de entender e analisar a história social do país, com certeza contribuiu para que além de compreendermos melhor o passado, possamos vislumbrar uma outra história para o futuro.

\section{NOTAS:}

1. Utilizaremos o termo radical como Michael Löwy utiliza em sua obra Para uma sociologia dos intelectuais revolucionários. A evolução política de Lukács (1909-1929), no qual ele utiliza o adjetivo para expressar a posição dos intelectuais que pretendem, no mínimo, questionar veementemente o capitalismo. Em suas palavras, "O intelectual 'radicalizado' é aquele que vê no capitalismo a causa profunda do 'mal da civilização', e que por isso deseja aboli-lo" (Löwy, 1979:4). 
2. A Academia Brasileira de Letras, durante as três primeiras décadas do século XX, foi uma das instituições culturais mais prestigiadas, e "lugar de fala" da intelectualidade brasileira. Temos que ressaltar que nesta época, a ABL ainda estava nos tempos áureos de sua existência, coisa que já não acontece atualmente.

3. Conclui sua graduação nove anos mais tarde.

4. O stalinismo, em sua forma mais ortodoxa, segundo Löwy, "implica a obediência acrítica e incondicional a todas as tendências e manobras da direção soviética e de seus instrumentos internacionais (Comintern, Cominform etc.)" (Löwy, 1979: 230).

5. Podemos dizer que a análise mouriana foi grandemente influenciada pela interpretação marxista caiopradiana.

6. Löwy analisa de forma bastante fecunda o que seria a categoria de intelectual e, teorizando, escreve: "Que é um intelectual? Trata-se, sem dúvida, de um ser bizarro e difícil de classificar. A primeira evidência é que o intelectual pode ser recrutado em todas as classes e camadas da sociedade: pode ser aristocrata (Tolstoi), industrial (Owen), professor (Hegel) ou artesão (Proudhon). Em outros termos: os intelectuais não são uma classe, mas uma categoria social; não se definem por seu lugar no processo de produção, mas por sua relação com as instâncias extra-econômicas da estrutura social; do mesmo modo que os burocratas e os militares se definem por sua relação com o político, os intelectuais situam-se por sua relação com a superestrutura ideológica. Quer dizer: os intelectuais são uma categoria social definida por seu papel ideológico: eles são os produtores diretos da esfera ideológica, os criadores de produtos ideológico-culturais" (Löwy, 1979:1).

7. De acordo com Madeira e Veloso (1999:180), foram nas décadas de 40 e 50 que as ciências sociais começaram a se institucionalizar, rompendo com a tradição "ensaística" dos anos de 20 e 30. Duas instituiçôes de ensino se destacaram: a USP - Universidade de São Paulo e o ISEB - Instituto Superior de Estudos Brasileiros, desde logo com posicionamentos distintos. Segundo as autoras, "a USP adota critérios que afirmam a autonomia da pesquisa acadêmica e da universidade diante de outras instâncias de poder, buscando pôr em prática um ethos e os procedimentos científicos internacionalmente válidos. Surge, nessa instituição, um grupo de pesquisadores, liderados por Florestan Fernandes, que garante a continuidade dos estudos sobre o modo de desenvolvimento do capitalismo no Brasil”. O ISEB, vinculado à estrutura do Ministério da Educação, por sua vez reúne um grupo de cientistas sociais, dentre eles, Guerreiro Ramos, Roland Corbisier, Nélson Werneck Sodré e Álvaro Vieira Pinto, que se propóem a elaborar um modelo de desenvolvimento para a sociedade brasileira. "Formulam também um tipo de ideal desenvolvimentista, entendido como possibilidade de inserção autônoma do país no sistema capitalista internacional. O grupo participa da elaboração do 'plano de metas' do governo do presidente Juscelino Kubitschek (1955-1960), responsável pelo surto modernizador do período” (ibidem:181). Ver mais sobre o assunto em Daniel Pécaut (1990).

8. Essa análise nos remete a Gramsci e seu conceito de “intelectual orgânico”, que se caracteriza justamente por intelectuais provenientes de um determinado grupo, e que passam a ser porta-vozes desta ou daquela organização social. Este conceito gramsciano cabe muito bem para caracterizarmos o intelectual Clóvis Moura, por suposto 


\section{Érika Mesquita}

“intelectual orgânico" de alguns movimentos negros, que trataremos adiante. Ver Gramsci (1978).

9. Na concisa interpretação de Florestan Fernandes, "O Estado é uma realidade histórica. Ele não existe e tampouco se transforma em si e por si. A primeira denúncia a ser feita contra um Estado que espolia os cidadãos de seus direitos, a Nação de seu caráter de comunidade nacional, e que só se realiza em favor do crescimento do privilégio e dos privilegiados, consiste em ressaltar que ele é usado socialmente contra a coletividade" (Fernandes, citado em Bosi, 1992:221).

10. Lembramos, aqui, do conceito foucaultiano de "formação discursiva", que nos permite analisar como surgem os discursos, e o peso relativo de cada discurso em determinada época histórica. Podemos sumariar que os discursos são representações cuja vigência dependerá do poder e da influência institucional que irá sustentá-la. Logo, o prestígio de tal ou qual representação depende do aval favorável da instituição encarregada de conferir este poder. No caso do discurso mouriano, não houve o aval da instituição encarregada do ordenamento e "controle" dos mesmos.

11. Moura contribuiu para retirar o véu da existência, no país, de uma democracia racial, enfocando que o capitalismo e a democracia são, por essência, contraditórios.

12. O estudo da resistência negra tenta ligar a forma e a freqüência dos atos rebeldes dos escravos a situações sociais e econômicas amplas.

\section{Referências Bibliográficas}

BOURDIEU, Pierre (1983). Questôes de sociologia. Rio de Janeiro, Editora Marco Zero.

CALDERANO, Maria Letícia Cotta (2002). Concepçôes e práticas do exercício do poder: a experiência vivida pela UNEGRO. Campinas, Unicamp, mimeo.

CANDIDO, Antônio (2000). Literatura e sociedade. São Paulo, Publifolha.

CARVALHO, José Murilo de (2001). Cidadania no Brasil. O longo caminho. Rio de Janeiro, Editora Civilização Brasileira.

COUTINHO, Carlos Nelson (2000). Cultura e sociedade no Brasil. Ensaio de idéias e formas. Rio de Janeiro, Editora DP\&A.

BOSI, Alfredo (1992). Cultura brasileira: temas e situaçôes. São Paulo, Editora Ática.

GARCIA, Marco Aurélio (1985). "Os intelectuais e os partidos de esquerda”. In M. S. A. Soares (org.), Os intelectuais nos processos políticos da América Latina. Porto Alegre, Editora da UFRGS.

GRAMSCI, Antônio (1978). Os intelectuais e a organização da cultura. Rio de Janeiro, Editora Civilização Brasileira.

GUIMARÁES, Carlos Magno (1983). Uma negação da ordem escravista: quilombos em Minas Gerais no século XVIII. Belo Horizonte, UFMG, mimeo. Primeira Edição em 1988 (São Paulo, Editora Ícone).

KONDER, Leandro (1991). Intelectuais brasileiros \& marxismo. Belo Horizonte, Oficina de Livros.

LÖWY, Michael (1979). Para uma sociologia dos intelectuais revolucionários. São Paulo, Lech Livraria Editora Ciências Humanas.

MESQUITA, Érika (2002). Clóvis Moura: uma visão crítica da história social brasileira. Campinas, Unicamp, mimeo. 
MOTA, Carlos Guilherme (org.) (1995). Brasil em perspectiva. Rio de Janeiro, Editora Bertrand Brasil. (2000). Ideologia da cultura brasileira (1933 - 1974). São Paulo, Editora Ática.

MOURA, Clóvis (1978). A sociologia posta em questão. São Paulo, Livraria Editora Ciências Humanas.

(1984). Os quilombos e a rebelião negra. São Paulo, Editora Brasiliense.

(1988). Rebelióes da senzala. Porto Alegre, Editora Mercado Aberto.

(1988). Sociologia do negro brasileiro. São Paulo, Editora Ática.

(1994). Dialética radical do Brasil negro. São Paulo, Editora Ática.

PÉCAUT, Daniel (1990). Os intelectuais e a política no Brasil. Entre o povo e a nação. São Paulo, Editora Ática.

PÊCHEUX, Michel (1990). O Discurso. Estrutura ou acontecimento. Campinas, Editora da Unicamp.

SAES, Décio Azevedo Marques de (1985). "Os intelectuais e suas associações”. In M. S. A. Soares (org.), Os intelectuais nos processos politicos da América Latina. Porto Alegre, Editora da UFRGS.

SCHWARCZ, Lilia Moritz (1987). O espetáculo das raças. São Paulo, Companhia da Letras.

SCHWARTZ, Stuart, B. (2001). Escravos roceiros e rebeldes. Bauru, SP, EDUSC.

VELOSO, Mariza e MADEIRA, Angélica (1999). Leituras brasileiras: itinerários no pensamento social e na literatura. Rio de Janeiro, Editora Paz e Terra. 